\title{
Sugar Smart, Heart Smart: The way Smart cities should be
}

\author{
Sanjay Kalra, Sumedha Kataria ${ }^{1}$, AK Pandey ${ }^{2}$, Rajiv Girdhar ${ }^{3}$, Asim Das ${ }^{4}$, Naresh Kardwal ${ }^{5}$ \\ Department of Endocrinology, Bharti Hospital, Karnal, India, ${ }^{1}$ Municipal Commisioner, Karnal, ${ }^{2}$ Department of Physiology, ESIC Medical \\ College, Faridabad, ${ }^{3}$ Department of Waste Disposal, Municipal Corporation, Karnal, ${ }^{4}$ Dean, ESIC Medical College, Faridabad, ${ }^{5}$ Medical Officer, \\ Civil Surgeon Office, Karnal, India
}

India' ambitious Smart Cities Mission hopes to create a hundred "smart cities," thus ushering in a new era of urban development in the country. ${ }^{[1]}$ Smart cities need smart citizens, and smart citizens need to be healthy. Healthy citizens need to enjoy good metabolic, endocrine, and vascular health as to limit the impact of noncommunicable disease (NCD) such as diabetes and heart disease. Therefore, smart cities need to be Sugar Smart and Heart Smart as well.

While there is no universal definition of a Smart city, Indian guidelines mention that such a city should provide core infrastructure and offer decent quality of life, lean and sustainable environment, and "smart" solutions to its citizens. The core infrastructure, which includes institutional, physical, social, and economic aspects, is representative of the entire urban eco-system. Among the ten core elements listed by the government of India as part of a Smart city's infrastructure is "health and education." ${ }^{[2]}$

Smart cities are also defined in terms of their information and communication infrastructure technology (ICT). ${ }^{[3]}$ Indian government guidance for smart cities suggests various ways in which smart cities may harness ICT. These methods are termed "smart solutions." The list of smart solutions includes telemedicine, among other. Smart cities can be identified by various characteristics, which spam all domains of infrastructure and life. Features of

\begin{tabular}{|l|l|}
\hline \multicolumn{2}{|c|}{ Access this article online } \\
\hline Quick Response Code: & Website: \\
\hline & www.josh.net \\
\hline & \\
\hline
\end{tabular}

a Smart city include creation of "walkable" localities, which include road networks for pedestrians, and cyclists; preservation and development of open spaces such as park, playgrounds, and recreational spaces; creation of a city identity, which may be based on health, and application of smart solutions in various spheres of life. ${ }^{[2]}$

What does "smart" mean? The dictionary defines the adjective as "quick or prompt in action," when applied to persons. ${ }^{[4]}$ Smart citizens, of a Smart city, therefore, should be quick or prompt in actions to various stimuli, including health-related issues. Smart citizens should be able to harness ICT utilizing available institutional physical, social, and economic infrastructure for their benefit. This should allow them to maintain optimal health, with full use of preventive and curative services.

In the urban context, NCD is now the leading cause of morbidity and mortality. Haryana's smart cities, Faridabad, and Karnal, for example, have the highest rates of obesity/overweight and diabetes in the state. ${ }^{[5]}$ Any mission that aims to create smart cities must necessarily produce smart citizens as well. Smart citizens must be health smart in general, and Sugar Smart and Heart Smart in specific, if they are to prevent, manage, and contain the epidemic of NCD.

\footnotetext{
This is an open access article distributed under the terms of the Creative Commons Attribution-NonCommercial-ShareAlike 3.0 License, which allows others to remix, tweak, and build upon the work non-commercially, as long as the author is credited and the new creations are licensed under the identical terms.
}

For reprints contact: reprints@medknow.com

How to cite this article: Kalra S, Kataria S, Pandey AK, Girdhar R, Das A, Kardwal N. Sugar smart, heart smart: The way smart cities should be. J Soc Health Diabetes 2016;4:51-4.

Corresponding Author: Dr. Sanjay Kalra, Department of Endocrinology, Karnal, Haryana, India. E-mail: brideknl@gmail.com 
We discuss the ways in which smart cities can make themselves Sugar Smart and Heart Smart entities while trying to create a checklist of their essential attributes [Table 1]. This will create better health for their inhabitants, and allow them to build a unique brand identity as well.

\section{INSTITUTIONAL INFRASTRUCTURE}

The city administration and health department should work in tandem to create institutional support for Heart Smart and Sugar Smart initiatives. Existing national programs ${ }^{[6]}$ such as National Program for Prevention and Control of Cancer, Diabetes, CVD and Stroke should be strengthened. Administration officers and health care professionals should be sensitized to the importance of NCD, and encouraged to integrate NCD care in all health-related activities. Newly launched initiatives such as Rashtriya Bal Swasthya Karyakram and Rashtriya Kishore Swasthya Karyakram, for example, can highlight ways to prevent and control childhood and adolescent obesity. At the other end of the life-cycle spectrum, the National Program for Health Care of Elderly can be used to improve awareness and management of diabetes and CVD. Similarly, gestational diabetes mellitus can be made a part of reproductive and maternal health services. Cancer can be made a focus area within the National Tobacco Control Program and Revised National Tuberculosis Control Program.

Medical and curative services for diabetes and heart disease should be freely available in Sugar Smart and Heart Smart cities. Both Karnal and Faridabad have government medical colleges, which provide yeoman care to people from both within and beyond their cities. While Karnal has the distinction of having the oldest Endocrine Care Center in Haryana, Faridabad is well-known for its multispecialty and heart care hospitals.

\section{PHYSICAL INFRASTRUCTURE}

To achieve health smart status, development of health-friendly infrastructure is mandatory. Urban planning or macro architecture, ${ }^{[7]}$ should encompass the development (and maintains) of parks, playgrounds, sports field, stadia, and gymnasia, which encourage urbanites to participate in games and sports. Pedestrian paths and cycling tracks should be created to facilitate safe and comfortable travel on foot or by bicycle. Even in areas which are resource-constrained, similar activities can be carried out. In Karnal, for example, certain roads are blocked for skaters in the early morning hours. The

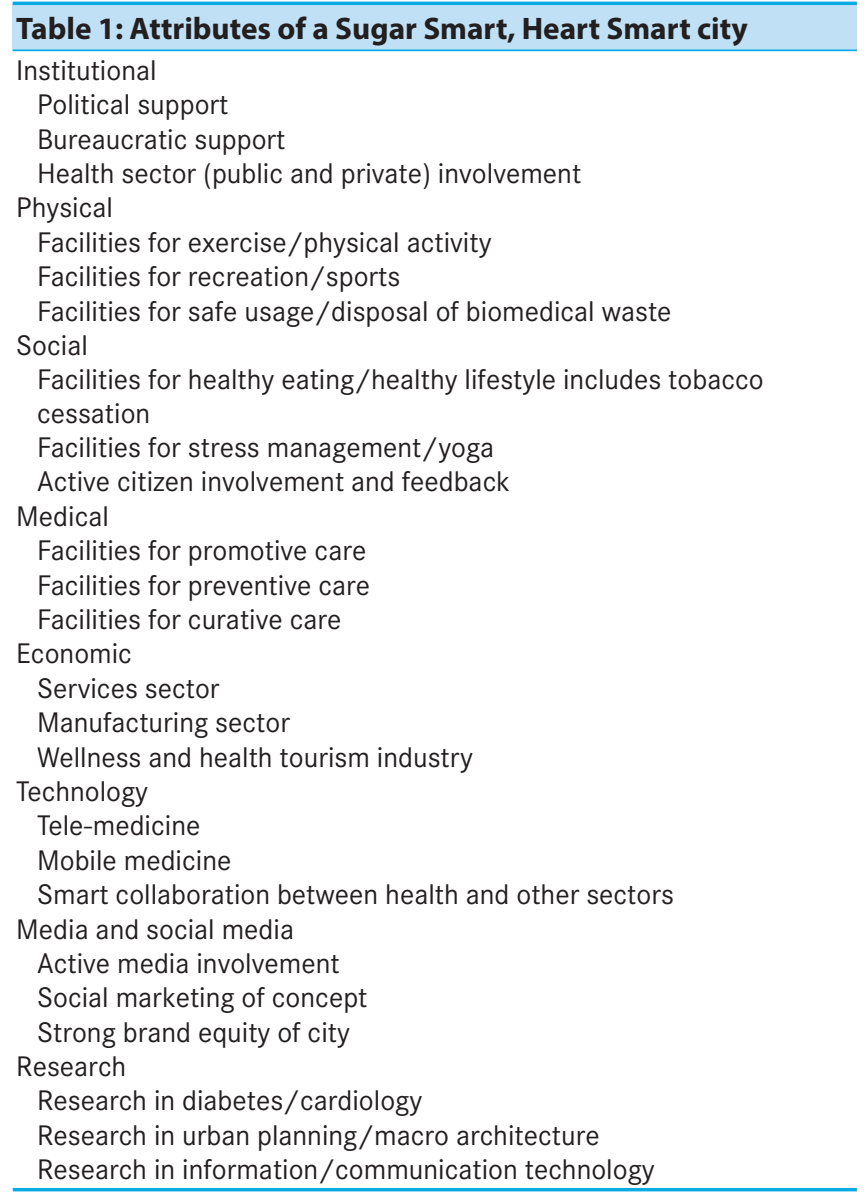

Raahgiri concept, popular in both Faridabad and Karnal, envisages "taking over" of roads on Sunday morning, by exercise and sports enthusiasts centrally-located public places have also been demarcated for yoga sessions. All these activities have spurred and physical fitness and can be intertwined to create a Sugar Smart or Heart Smart movement.

\section{SOCIAL INFRASTRUCTURE}

Smart cities exist for societies, and it is societies or people, which make a city smart. Social involvement and development are essential in order for a city to achieve smart status.

Various organizations such as faith-based groups, nongovernmental associations, resident welfare associations, social clubs, women's groups, and professional guilds can be used to spread knowledge and awareness about Sugar Smart and Heart Smart initiatives, and improve practices related to the same. While such efforts are already underway, the respected Prime Minister's call for focusing on diabetes prevention, through yoga, is expected to provide the much-needed 
fillip to them. ${ }^{[8]}$ It must be ensured that his message is extrapolated to include other aspects of lifestyle, such as physical activity, stress management, and sleep hygiene. All these components must be addressed and optimized to limit NCD progression.

Social involvement is extremely important to achieve these goals. Diabetes-friendly or low-fat food should be available at restaurants, canteens, and hotels; similar options should be serves at social gatherings and functions. A Smart city might wish to create a Sugar Smart or Heart Smart logo, akin to symbols for vegetarian and nonvegetarian food. These logos can be displayed by interested food outlets which serve healthy food. Facilities for medication and relaxation should be created, perhaps in conjunction with religious and spiritual organizations. The health sector, both public and private, should also ensure delivery of mental health care through qualified and trained professionals. This can be done by strengthening the National Mental Health Care Program in Smart cities. A sensitization drive, encouraging inhabitants to reduce noise pollution, by avoiding unnecessary honking of vehicle horns, and encouraging healthy sleep patterns, will also contribute to better metabolic health.

Although nonsequitur, mention must be made about smart disposal of insulin ancillaries and sharps, also termed as "green diabetology." ${ }^{\text {[9] }}$ A Sugar Smart city should be able to dispose of all biomedical waste, including sharps, in a safe and efficient manner. The Karnal Municipal Corporation drive to encourage segregation of waste, at source, is a welcome step.

\section{ECONOMIC INFRASTRUCTURE}

The Sugar Smart and Heart Smart movements have a symbiotic, mutually beneficial relationship with economic success. Thus, they contribute to the growth of a Smart city. Certainly, basic economic infrastructure is required to begin working on the multiple physical and social requirements of a healthy city. Once this is met, however, Heart Smart and Diabetes Smart cites can create unlimited opportunities for economic growth. They improve productivity by limiting the impact of preventable complications of diabetes and heart disease in the working population. ${ }^{[10]}$ Less money spent on disease complications translates into more disposable income, which fuels local economy.

Such campaigns, though social marketing, promote the demand for promotive, preventive, and curative health service while creating ancillary wellness and health product industry. With the right support, such industries can generate gainful employment for educated citizens, spur medical tourism (both domestic and international), formulate a brand identity for the city, and contribute to revenue. This virtuous cycle, once started, expands both horizontally and vertically. It includes surrounding villages, towns, and cities, which provide manpower and manufacturing facilities, in its ambit. It also grows vertically, pushing the envelope to amalgamate innovative industries such as yoga, wellness spas, healthy food, footwear, sportswear, and the like.

\section{The Potential of Technology}

Smart cites thrive on ICT. ${ }^{[1]}$ ICT has virtually unlimited applications in the content of Sugar Smart and Heart Smart cities. A patient with myocardial infarction, for example, who is being transferred to a tertiary care center, may benefit from collaboration between smart health and smart traffic authorities. The departure of his ambulance should be able to trigger a series of sensors and commands, allowing traffic lights to be adjusted so as to allow the ambulance to reach its destination without impedance.

Similarly, detection of an unexpectedly dense cluster of people with diabetes should automatically alert authorities to the need preventive strategies in that locality. It should also help map health care requirements, so as to facilitate the provision of appropriate health care facilities while optimizing the use of available resources.

\section{SOCIAL MARKETING}

Social marketing is frequently used to promote public health, and India is a trailblazer in this field. ${ }^{[12]}$ Heart Smart and Sugar Smart cities require social marketing to present their case. The role of mass media, including print, television, radio and online channels, cannot be understated both Faridabad and Karnal enjoy vibrant media, which play their role in promoting healthy living. Such media, including FM radio, can be tapped to spread the message of Sugar Smart and Heart Smart living.

\section{RESEARCH}

Smart cities are expected to be leaders of innovation and change, acting as catalysts for improvement. It is expected, therefore, that scientists, architects, urban planners, ICT researchers, and medical professionals of these cities take active interest in research. Work needs to be done to identify knowledge gaps related to Sugar Smart and Heart 
Smart concepts and fill them. Translational research is also necessary to develop indigenous models of urban health care and development.

\section{CONCLUSION}

The concept of Sugar Smart and Heart Smart cities is a pragmatic one. This strategy, if implemented properly, has the potential to improve not only NCD care and health in urban settings, but also contribute to urban growth. Detailed attention to these proposals, including them as an integral part of Smart City development, is the need of the hour.

\section{Financial support and sponsorship}

Nil.

\section{Conflicts of interest}

There are no conflicts of interest.

\section{REFERENCES}

1. Coverage and Duration. Available from: http://www.smartcities. gov.in/SmartCitiesPPT/Slide1.JPG. [Last accessed on 2016 Jun 26].
2. Smart City Guidelines. Available from: http://www.smartcities. gov.in/writereaddata/SmartCityGuidelines.pdf. [Last accessed on 2016 Jun 26].

3. Solanas A, Patsakis C, Conti M, Vlachos IS, Ramos V, Falcone F, et al. Smart health: A context-aware health paradigm within smart cities. IEEE Commun Mag 2014;52:74-81.

4. Smart. Available from: http://www.dictionary.com/browse/ smart?s=t. [Last accessed on 2016 Jun 26].

5. Kumar A, Kalra S, Unnikrishnan AG. Metabolic state of the nation: Results of the national family health survey-4. Indian J Endocrinol Metab 2016;20:429-31.

6. Shriraam V, Mahadevan S, Anitharani M, Selvavinayagam, Sathiyasekaran B. National health programs in the field of endocrinology and metabolism - Miles to go. Indian J Endocrinol Metab 2014;18:7-12.

7. Kumar KM, Raghupathy P, Kalra S. Diabetes-friendly environments for children with diabetes. Indian J Endocrinol Metab 2015;19 Suppl 1:S1-3.

8. Text of PM's "Mann ki Baat" Programme on All India Radio on; 26 June, 2016. Available from: http://www.pib.nic.in/newsite/ PrintRelease.aspx?relid=146513. [Last accessed on 2016 Jun 26].

9. Kalra S, Girdhar R, Sahay R. Green diabetology. Indian J Endocrinol Metab 2015;19:698-700.

10. Sahay R, Baruah MP, Kalra S. Health economics in India: The case of diabetes mellitus. Indian J Endocrinol Metab 2014;18:135-7.

11. Mandel JC, Kreda DA, Mandl KD, Kohane IS, Ramoni RB. SMART on FHIR: A standards-based, interoperable apps platform for electronic health records. J Am Med Inform Assoc 2016. pii: Ocv189.

12. Kalra S, Sahay R. Timely insulin use: Need for social marketing. Indian J Endocr Metab 2016 [Ahead of Print]. 